\title{
COMPARATIVE STUDIES ON HEPATIC N- AND O-DEMETHYLATION
}

\author{
Hatsue OHTSUJI*, Toshiko IMAMURA and Masayuki IKEDA \\ Department of Public Health, Faculty of Medicine, Kyoto University, \\ Sakyo-ku, Kyoto, Japan
}

Received for publication February 5, 1972

Oxidative dealkylation is an important step in the metabolism of various foreign compounds including a number of clinically useful drugs (1). Studies to establish a comparison between aromatic hydroxylation of aniline and side chain hydroxylation at methyl moiety of p-nitrotoluene (2) are further extended in the present report to other types of microsomal oxidative reactions, i.e., $\mathrm{N}$ - and $\mathrm{O}$-demethylation, the two possible variations of hydroxylation (1).

\section{MATERIALS AND MLTHODS}

\section{Chemicals}

Para-chloro-N-methylaniline was synthesized by Dr. S. Uemura of Institute for Chemical Research, Kyoto University, Kyoto, after the method of Roberts and Vogt (3). The following reagents were granted: Aminoantipyrine, 4-monomethylaminoantipyrine and 4-dimethylaminoantipyrine (aminopyrine) from Nippon Shinyaku Co., Kyoto; tolbutamide (1-butyl-3-p-tolylsulfonylurea) from Ono Pharmaceutical Co., Osaka; hydroxymethyltolbutamide (1-butyl-3-p-hydroxymethylphenylsulfonylurea) from Boehringer Mannheim Japan, Tokyo; SKF 525-A (2-diethylaminoethyl 2, 2-diphenyl valerate hydrochloride), SKF 8427 A (2-ethylaminoethyl 2, 2-diphenyl valerate hydrochloride) and AEDV (aminoethyl 2, 2diphenyl valerate) from Smith, Kline and French Laboratories, Philadelphia, Pa., U.S.A.; Lilly 18947 (2, 4-dichloro-6-phenylphenoxyethyl diethylamine hydrobromide), Lilly 38704 (2, 4-dichloro-6-phenylphenoxyethyl elhylamine hydrobromide) and DPEA (2, 4-dichlorophenylphenoxyethylamine) from Lilly Research Laboratories, Indianapolis, Ind., U.S.A.; metyrapone (2-methyl-1, 2-di-3-dipyridyl-1-propanone) from Ciba-Geigy Ltd., Basel, Switzerland; MG 3062 (phenyl-(4-chlorophenyl)-4-piridylmethanol) from Magrgioni \& C.S.p.A., Milano, Italy. p-Anisidine (p-methoxyaniline) hydrochloride, aniline and others were obtained from commercial sources.

\section{Animals}

Female Wistar rats (weighing about $50 \mathrm{~g}$ ) were maintained on laboratory chow and

This work was supported in part by a grant from the Fujiwara Memorial Fund.

Request reprints from : M. Ikeda, Department of Public Hcalth, Kyoto University, Faculty of Medicine, Sakyo-ku, Kyoto, Japan.

* Present address : Saku General Hospital, Usuda-cho, Nagano Prefecture, Japan. 
water ad libitum. In some instances they were pretreated ip with either phenobarbital (75 mg/kg daily for 4 days, (4) ) or 3-methylcholanthrene (single dose of $20 \mathrm{mg} / \mathrm{kg}$, (5)), and sacrified $24 \mathrm{hr}$ after the last injection.

Assays of activities for demethylation and other reactions

Unless otherwise specified, the liver from the phenobarbital-pretreated rat was studied. The $10,000 \mathrm{~g}$ supernatant fraction $(3 \mathrm{ml}$ of which were cquivalent to $1 \mathrm{~g}$ of wet liver) was prepared as described previously (6). Incubations were in air at $37^{\circ}$. Composition of the standard incubation mixture, in a final volume of $2.0 \mathrm{ml}$ in general, was as described by Gillette for $p$-nitrotoluene hydroxylation (7) except that various compounds were added as substrates in the place of $p$-nitrotoluene.

$\mathrm{N}$-demethylation of $p$-chloro- $\mathrm{N}$-methylaniline was assayed by the method of Kupfer and Bruggeman (8) with $6 \%$ p-dimethylaminobenzaldehyde in $3 \mathrm{~N} \mathrm{H}_{2} \mathrm{SO}_{4}$ as a colourdeveloping reagent. When added to the solution containing aminoantipyrine, the $p$ dimethylaminobenzaldehyde reagent gave rise to quantitative coloration with absorption maximum at $445 \mathrm{~m}$ \%. Much less colour resulted using monomethylaminoantipyrine. In light of this observation, the method of Kupfer and Bruggeman was employed for the assay of monomethylaminoantipyrine $\mathrm{N}$-demethylation under the assumption that increase in colour intensity at $445 \mathrm{~m}$ / after incubation was attributable to aminoantipyrine formation.

The amount of $p$-aminophenol was measured for the assay of $p$-anisidine $O$-demethylation activity (9) by the method of Imai and Sato (10) originally developed for the assay of aniline hydroxylation.

O-demethylation of $o$-nitroanisole was assayed by the measurement of $o$-nitrophenol after Netter (11), except that the reaction was stopped by the addition of $1.5 \mathrm{ml}$ of $12.5 \%$ trichloroacetic acid to a triple-scaled $(6.0 \mathrm{ml})$ incubation mixture. After centrifugation, $0.5 \mathrm{ml}$ of $40 \% \mathrm{Na}_{2} \mathrm{CO}_{3} \cdot 10 \mathrm{H}_{2} \mathrm{O}$ was added to $3.0 \mathrm{ml}$ of the supernatant solution to bring the $\mathrm{pH}$ to 8 with the resulting yellow colour being moasured at $420 \mathrm{~m} / \mathrm{s}$.

The formation of phenol from benzene was measured with Gibbs' reagent $0.2 \%$ 2,6-dichloroquinone chlorimide in ethyl alcohol) (12). Benzene solution in water was prepared by vigorous shaking of 1 portion of benzene with 1,000 portions of water for $15 \mathrm{~min}$ and added to the standard reaction mixture to give a final concentration of $8.5 \times 10^{-3} \mathrm{M}$. The reaction in triple scale $(6.0 \mathrm{ml})$ was terminated by heating the mixture in a boiling water bath for $3 \mathrm{~min}$, followed by centrifugation. To the supernatant liquid, $3.0 \mathrm{ml}$, was added $0.6 \mathrm{ml}$ of $4 \% \mathrm{Na}_{2} \mathrm{CO}_{3} \cdot 10 \mathrm{H}_{2} \mathrm{O}$ to adjust the $\mathrm{pH}$ to 10 , and $0.1 \mathrm{ml}$ of $0.2 \%$ Gibbs' reagent in ethyl alcohol. The resulting blue colour was measured at $610 \mathrm{~m} \ell$ after standing at room temperature for $60 \mathrm{~min}$.

Conversion of tolbutamide to hydroxymethyltolbutamide (i.e. hydroxylation of tolbutamide at the methyl group attached to benzene ring) was studied after Tagg et al. (13) with nonradioactive substrate at a final concentration of $2.6 \times 10^{-4} \mathrm{M}$. Incubation in 4-fold scale $(8.0 \mathrm{ml})$ was slopped by the addition of $3.2 \mathrm{ml}$ of $3 \mathrm{~N} \mathrm{HCl}$ and the precipitate removed by centrifugation. The supernatant solution was washed 4 times with 4 yolumes of $n$ - 
TABLF 1. Assay conditions.

\begin{tabular}{|c|c|c|c|c|}
\hline Reactions & Substrates & $\begin{array}{l}\text { Total volume } \\
\text { of incubation }\end{array}$ & $\begin{array}{c}\text { Hepatic } \\
\text { preparation } \\
\text { added* }\end{array}$ & $\begin{array}{l}\text { Incubation } \\
\text { duration }\end{array}$ \\
\hline \multirow{3}{*}{$\mathrm{N}$-demethylation } & & $(\mathrm{ml})$ & $(\mathrm{mg})$ & $(\min )$ \\
\hline & $p$-Chloro-N-methylaniline & 2.0 & 33 & 10 \\
\hline & Monomethylaminoantipyrine & 2.0 & 66 & 15 \\
\hline \multicolumn{5}{|l|}{ O-demethylation } \\
\hline & p-Anisidine & 2.0 & 66 & 15 \\
\hline & $o$-Nitroanisole & 4.0 & 66 & 10 \\
\hline \multicolumn{5}{|l|}{ Hydroxylation } \\
\hline & Benzene & 6.0 & 33 & 5 \\
\hline & Tolbutamide & 8.0 & 266 & 30 \\
\hline
\end{tabular}

* Wet liver wt.

heptane containing $1.5 \%$ isoamyl alcohol by vigorous shaking for $10 \mathrm{~min}$ to remove remaining tolbutamide (hydroxymethyltolbutamide formed was not washed out (13)). The hydroxymethyltolbutamide in $5 \mathrm{ml}$ of the washed solution was extracted into $16 \mathrm{ml}$ of ether. The ether, $15 \mathrm{ml}$, was transferred to a test tube containing $4 \mathrm{ml}$ of water and evaporated in a water bath at 60 . Absorption due to hydroxymethyltolbutamide in the water was

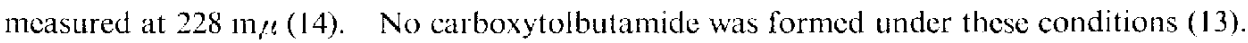

Incubation duration, the amount of hepatic preparation used, as well as the final volume of the incubation mixture are listed in Table 1. Under these conditions employed, the amounts of metabolites formed were proportional to the amounts of the hepatic preparation added as well as the duration of incubation.

\section{$\mathrm{Km}$ and $\mathrm{Ki}$ determinations}

Kinetic parameters were determined by double reciprocal plottings of substrate concentrations against velocities of reaction with and without inhibitors (15). Lines were drawn by least-square fitting when necessary.

\section{RESULTS}

1) Changes in kinetic paraneters after pretreatments with phenobarbital and 3-methylcholanthrene

Pretreatment of rats with phenobarbital resulted in approx. a 4-fold increasc in Vmax of monomethylaminoantipyrine demethylation activity and was as high as 9 times with $p$-chloro- $\mathrm{N}$-methylaniline, the difference between the two rates of enhancement being statistically significant $(\mathbf{P}<0.05)$ (Table 2$). \mathrm{Km}$ values remained essentially unchanged. 3-methylcholanthrene was apparently ineflective in increasing activity to demethylate monomethylaminoantipyrine, and gave only slight changes in $\mathrm{Km}$ and $\mathrm{V}$ max of $p$-chloro- $\mathrm{N}$-methylaniline demethylation. The effect of phenobarbital pretreatment on the Vmax of p-anisidine O-demethylation was comparable to that of monomethylaminoantipyrine $\mathrm{N}$-demethylation and less than that of $p$-chloro- $\mathrm{N}$-methylaniline $\mathrm{N}$-demethylation. Higher increases in Km (approx. 3-times) and $V \max$ (approx. 4-times) were achieved with 3-methylcholanthrene 


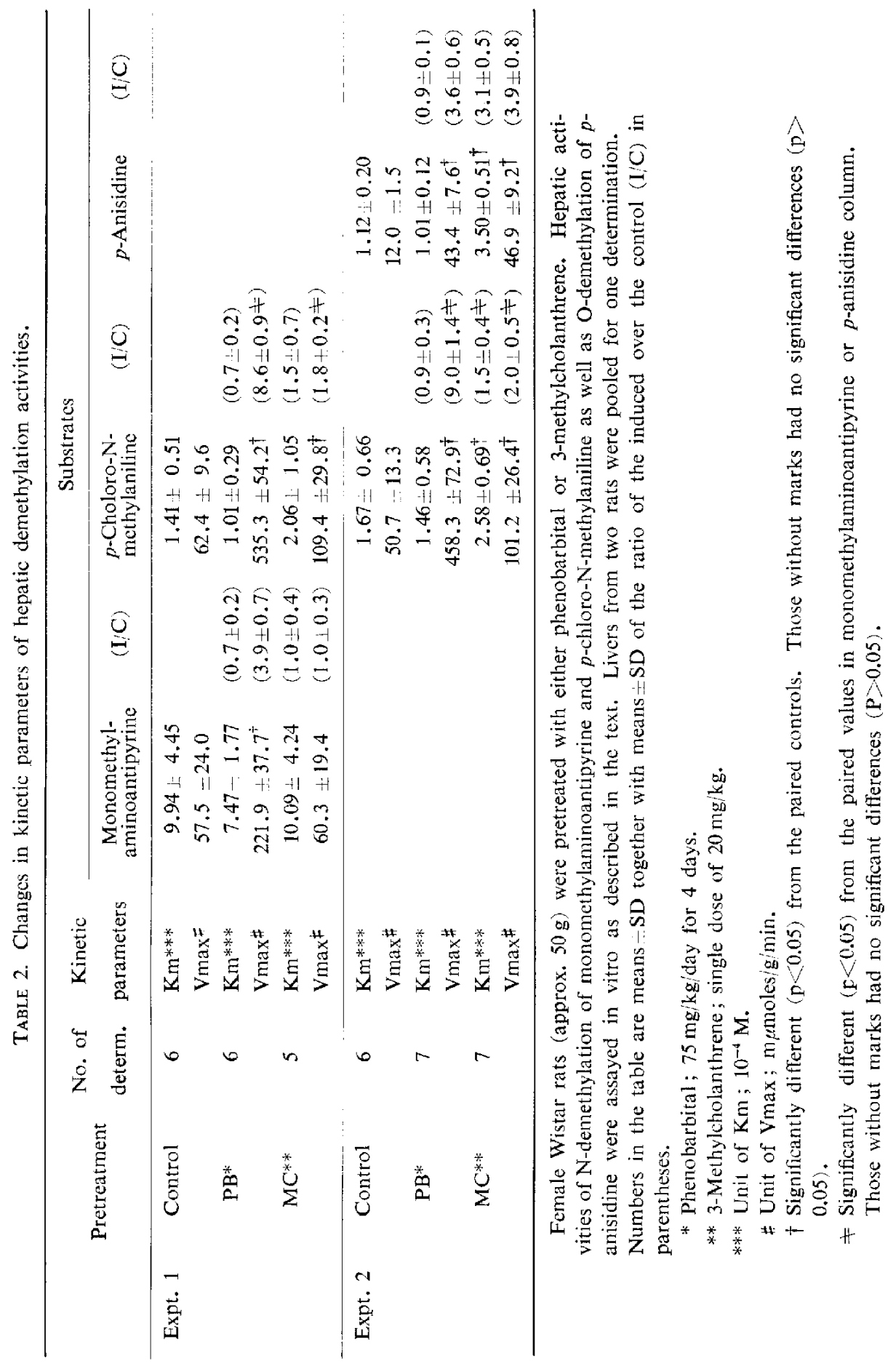


Table. 3. Types and inhibition constants with various inhibitors.

\begin{tabular}{|c|c|c|c|c|c|c|}
\hline \multirow[b]{2}{*}{ Inhibitors } & \multicolumn{4}{|c|}{$\mathrm{N}$-demethylation } & \multirow{2}{*}{\multicolumn{2}{|c|}{$\begin{array}{c}\text { O-demethylation } \\
\text { p-Anisidine } \\
\text { - }\end{array}$}} \\
\hline & & $\begin{array}{c}\text { Monomethylamino- } \\
\text { antipyrine }\end{array}$ & & Chloro-N-methylaniline & & \\
\hline AEDV & $\mathbf{N}$ & $6.5 \pm 1.2 \times 10^{-6} \mathrm{M}(6)$ & $\mathrm{N}$ & $4.5-0.2 \times 10^{-\vec{t}} \mathrm{M}$ & $N$ & $7.7 \pm 0.9 \times 10^{-6} \mathrm{M}$ \\
\hline SKF 8742-A & $N$ & $3.7 \pm 0.6 \times 10^{-6} \mathrm{M}(6)$ & $\mathrm{C}$ & $6.6 \div 0.7 \times 10^{-6} \mathrm{M}$ & $N$ & $7.1 \perp 0.8 \times 10^{-6} \mathrm{M}$ \\
\hline SKE 525-A & $\mathbf{N}$ & $5.4+1.4 \times 10^{-6} \mathrm{M}(7)$ & $\mathrm{C}$ & $1.0 \pm 0.3 \times 10^{-6} M(5)$ & $N$ & $7.1=0.5 \times 10^{-5} \mathrm{M}$ \\
\hline DPEA & $\mathbf{N}$ & $5.6 \pm 1.4 \times 10^{-6} \mathrm{M}(5)$ & $\mathrm{N}$ & $5.3 \div 1.2 \times 10^{-7} \mathrm{M}(7)$ & $N$ & $4.1 \pm 1.0 \times 10^{-5} \mathrm{M}(4)$ \\
\hline Lilly 38704 & $\mathrm{C}$ & $2.2 \pm 0.5 \times 10^{-6} \mathrm{M}(5)$ & $\mathbf{C}$ & $7.3 \div 0.9 \times 10^{-7} \mathrm{M}$ & $N$ & $2.5 \div 0.8 \times 10^{-5} \mathrm{M}(4)$ \\
\hline Lilly 18947 & $\mathrm{C}$ & $4.8 \perp 1.1 \times 10^{-6} \mathrm{M}(6)$ & $\mathrm{C}$ & $2.4 \perp 0.7 \times 10^{-6} \mathrm{M}(5)$ & $\mathrm{N}$ & $3.3: 0.7 \times 10^{-4} \mathrm{M}$ \\
\hline MG $3062^{*}$ & $N$ & $1.6 .10 .4 \times 10^{-5} \mathrm{M}(6)$ & $\mathrm{N}$ & $1.7 \div 0.1 \times 10^{-6} \mathrm{M}(5)$ & & hasic** \\
\hline Mityrapone & $\mathrm{C}$ & $6.2+0.8 \times 10^{-5} \mathrm{M}(6)$ & $\mathrm{N}$ & $4.8=0.8 \times 10^{-6} \mathrm{M}$ & $\mathrm{C}$ & $2.4-0.7 \times 10^{-4} \mathrm{M}(6)$ \\
\hline
\end{tabular}

Experiments were conducted with the preparation from the livers of young female rats pretreated with phenobarbital as described under Materials and Methods. Numbers in the table are means $=$ SD together with numbers of determinations in parentheses. $\mathrm{C}$ and $\mathrm{N}$ stand for competitive and non-competitive type inhibition, respectively.

* Acetone, $2 \%$, was added to dissolve the inhibitor.

* See Fig. 3 for details.

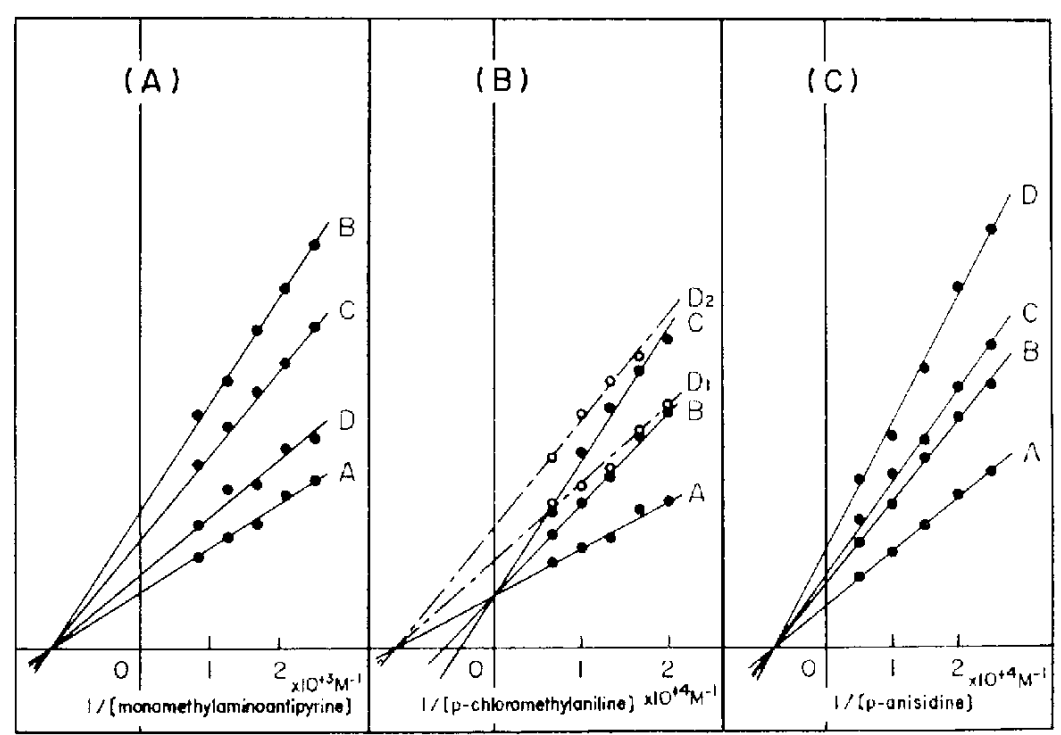

Fuc. 1. In vitro effects of SKF 525-A and its analogues on $\mathrm{N}$-and O-demethylation reactions.

Incubation was as described under Materials and Methods.

(A) Double reciprocal plots of monomethylaminoantipyrine concentration versus rate of $\mathrm{N}$-demethylation. Inhibitors added are as follows: $\mathrm{A}$, none (control); B, SKF $525-\mathrm{A}$ at $5.0 \times 10^{-8} \mathrm{M}$; C, SKF $8742-\mathrm{A}$ at $2.5 \times 10^{-6} \mathrm{M} ; \mathrm{D}$, AEDV at $2.5 \times 10^{-6} \mathrm{M}$.

(B) Double reciprocal plots of $p$-chloro-N-methylaniline concentration varsus rate of N-demethylation. Inhibitors added are as follows: $A$, none (control); B, SKF 525-A at $1.25 \times 10^{-6} \mathrm{M}$; C, SKF 8742-A at $1 \times 10^{-6} \mathrm{M} ; \mathrm{D}_{1}$, AEDV at $2.5 \times 10^{-7} \mathrm{M} ; \mathrm{D}_{2}$, ibid at $5 \times 10^{-7} \mathrm{M}$.

(C) Double reciprocal plots of $p$-anisidine concentration versus rate of $\mathrm{O}$ demethylation. Inhibitors added are as follows: $\mathrm{A}$, none (control); $\mathrm{B}, \mathrm{SKF}$ 525-A at $2.3 \times 10^{-6} \mathrm{M}$; C, SKF $8742-\mathrm{A}$ at $5 \times 10^{-6} \mathrm{M} ; \mathrm{D}, \mathrm{AEDV}$ at $5 \times 10^{-6} \mathrm{M}$. 


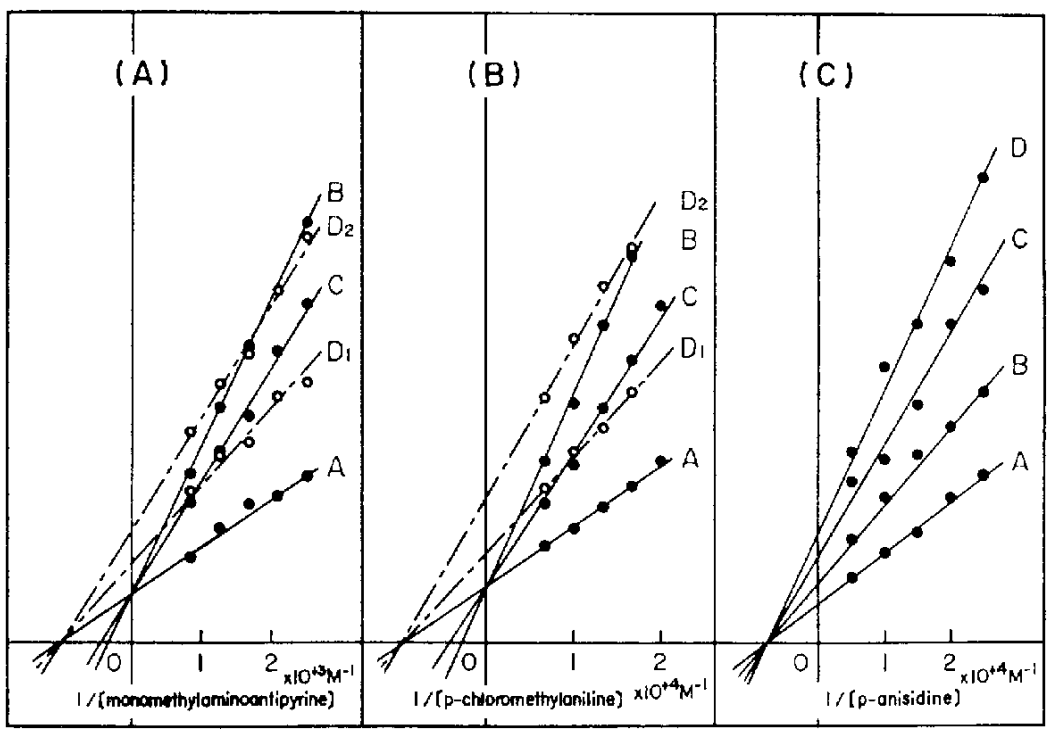

FIG. 2. In vitro effects of Lilly 18947 and its analogues on $\mathrm{N}$ - and O-cemethylation reactions.

Incubation was as described under Materials and Methods.

(A) Double reciprocal plots of monomethylaminoantipyrine concentration versus rate of $\mathrm{N}$-demcthylation. Inhibitors added are as follows: $\mathrm{A}$, none (control); B, Lilly 18947 at $1 \times 10^{-5} \mathrm{M} ; \mathrm{C}$, Lilly 38704 at $2 \times 10^{-6} \mathrm{M} ; \mathrm{D}_{1}$, DPEA at $2.5 \times 10^{-6} \mathrm{M} ; \mathrm{D}_{2}$, ibid at $5 \times 10^{-6} \mathrm{M}$.

(B) Double reciprocal plots of $p$-chloro-N-methylaniline concentration versus rate of $\mathrm{N}$-demethylation. Inhibitors added are as follows: $\mathrm{A}$, none (control); B, Lilly 18947 at $2 \times 10^{-6} \mathrm{M} ; \mathrm{C}$, Lilly 38704 at $2 \times 10^{-6} \mathrm{M} ; \mathrm{D}_{1}$, DPEA at $2 \times 10^{-7}$ $\mathrm{M} ; \mathrm{D}_{2}$, ibid at $4 \times 10^{-7} \mathrm{M}$.

(C) Double reciprocal plots of $p$-anisidine concentration varsus rate of $\mathrm{O}$ demethylation. Inhibitors added are as follows: A, none (control) ; B, Lilly 18947 at $2 \times 10^{-4} \mathrm{M} ; \mathrm{C}$, Lilly 38704 at $1 \times 10^{-1} \mathrm{M}: \mathrm{D}$, DPEA at $1 \times 10^{-1} \mathrm{M}$.

pretreatment in $p$-anisidine $\mathrm{O}$-demethylation, when compared with 1.5-times increase in $\mathrm{Km}$ and 2 -times increase in $\mathrm{Vmax}$ of $p$-chloro- $\mathrm{N}$-methylaniline $\mathrm{N}$-demethylation. As a whole, phenobarbital pretreatment resulted in the greatest change in $V \max$ of $p$-chloro- $N$ methylaniline $\mathrm{N}$-demethylation among the three reactions studied, while $\mathrm{Km}$ values remained almost unchanged. With 3-methylcholanthrene pretreatment, changes in kinetic parameters were most evident in p-anisidine O-demethylation.

2) Changes in demethylation kinetics by inhibitors and other shemicals

As shown in Table 3, AEDV and its ethyl derivatives inhibited all three demethylation reactions around the order of $10^{-6} \mathrm{M}$ in a non-competitive manner cxcept that $p$-chloro$\mathrm{N}$-methylaniline demethylation was competitively inhibited by SKF 525-A and SKF 8742A (Fig. 1). N-demethylation reactions of both monomethylaminoantipyrine and $p$ chloro-N-methylaniline were competitively inhibited by Lilly 18947 and Lilly 38704 in the order of $10^{-6} \mathrm{M}$ non-competitively by DPEA at about $10^{-6} \mathrm{M}$ (Fig. 2). DPEA and its derivatives were less inhibitory on $p$-anisidine $\mathrm{O}$-demethylation, the inhibtion types being 
all non-competitive. The sharpest contrast between $\mathrm{N}$ - and $\mathrm{O}$-demethylation was observed with MG 3062. This compound was a potent inhibitor of the two N-demethylation reactions; $\mathrm{Ki}$ was $1.6 \times 10^{-5} \mathrm{M}$ when monomethylaminoantipyrine was studied, and was as low as $2 \times 10^{-6} \mathrm{M}$ with $p$-chloro- $\mathrm{N}$-methylaniline. However, MG 3062 at $2 \times 10^{-4} \mathrm{M}$ inhibited $p$-anisidine demethylation only by $50 \%$ at a theoretical infinite concentration of the substrate, and did stimulate the same reaction by $33 \%$ at the substrate concentration of $4 \times 10^{-5} \mathrm{M}$. Regression lines of the double reciprocal plots of the results with and without MG 3062 met together in the right upper quadrant of the figure (Fig. 3). Metyrapone, a diphastic modifier of acetanilide hydroxylation (16), did not stimulate any of the three reactions but inhibited them at rather high concentrations.

\section{3) Effect of acetone on demethylation and hydroxylation reations}

Among the reactions studied, stimulatory effect of acetone $(1,17)$ was observed only in p-anisidine O-demethylation (Fig. 4); the presence of $2 \%$ acetone gave an enhancement of the activity by $68 \%$ at the theoretical infinite concentration of the substrate. The same concentration of acetone produced no stimulation in O-demethylation of $o$-nitroanisole, $\mathrm{N}$-demethylation of monomethylaminoantipyrine and $p$-chloro- $\mathrm{N}$-methylaniline, aromatic hydroxylation of benzene nor hydroxylation of tolbutamide at methyl group.

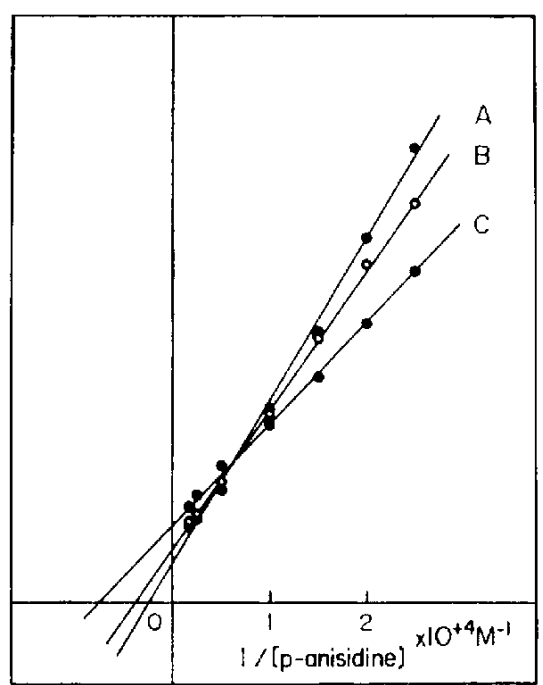

FIG. 3. In vitro effect of MG 3062 on $\mathrm{O}$ demethylation of $p$-anisidine.

Incubation was as described under $M a$ terials and Methods except that acetone was added a the final concentration of $2 \%$. Concentrations of $p$-anisidine are double-reciprocally plotted versus O-demethylation activity. MG 3062 concentration ; (A) none, (B) $2.2 \times 10^{-5} \mathrm{M}$ and (C) $2.2 \times 10^{-4} \mathrm{M}$.

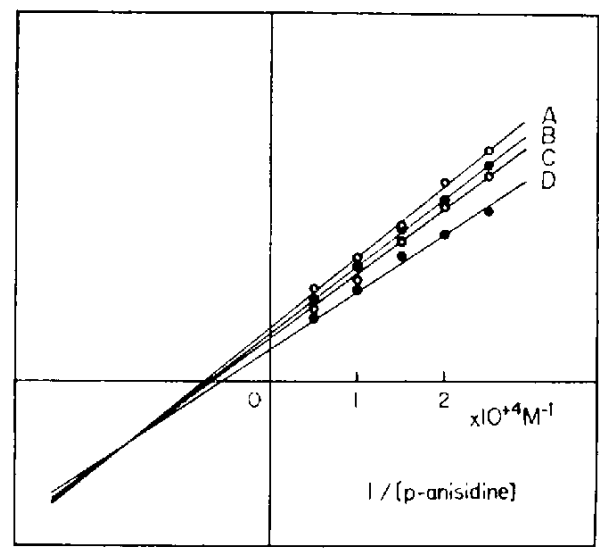

Fic. 4. In vitro effect of acetone on $\mathrm{O}$-demethylation of $p$-anisidine.

Incubation was as described under $\mathrm{Ma}$ terials and Methods. Concentrations of $p$-anisidine are double-reciprocally plotted versus $\mathrm{O}$-demethylation activity. Acetone concentrations; (A) none, (B) $0.5 \%$, (C) $1 \%$ and (D) $2 \%$. 


\section{DISCUSSION}

Characteristics were compared among three popular demethylation reactions i.e., $\mathrm{N}$-demethylation of monomethylaminoantipyrine and $p$-chloro- $\mathrm{N}$-methylaniline, and $\mathrm{O}$ demethylation of $p$-anisidine. Results summarized in Table 2 indicate that responses of the three reactions toward the inductive effects of phenobarbital and 3-methylcholanthrene were different and no cluar parallelism was observed among increases in the activities of the three reactions; the highest enhancement after phenobarbital pretreatment was observed in Vmax of $p$-chloro- $N$-methylaniline demelhylation while the activity for $p$-anisidine demethylation was most responsive when the animals were given 3-methylcholanthrene. Suppressive effects of inhibitors also varied depending on the demethylation reaction studied (Table 3). These findings appear to suggest that different enzyme systems or rate limiting components are involved in the three demethylation reactions.

Apart from O-demethylation reation, the two $\mathrm{N}$-demethylation ractions share the same responses to the inhibitors examined except those for SKF 8742-A and SKF 525-A. This observation is in accordance with the reports $(18,19)$ on the comparison between $O$ dcalkylation of norcodeine and N-dealkylation of ethylmorphine. SKF 525-A, together with SKF 8742-A, inhibited $p$-chloro-N-methylaniline demethylation compelitively as reported on ethylmorphine dealkylation (20) and monomethylaninoantipyrine demethylation noncompetitively, while DPEA derivatives inhibited the wo N-demethylation reactions in competitive manners. This discrepancy in the inhibition pattern between the ethyl derivatives of AEDV and DPEA could be attributed to chemical structure differences other than the di- or tri-ethylamine moiety in these compounds.

An apparent agreement was found in the mode of inhibition of various chemicals between aromatic hydroxylation of aniline (2) and $p$-anisidine O-demethylation. All of AEDV, DPEA and their ethyl derivatives inhibit the two reactions noncompetitively, and metyrapone was the common competitive inhibitor to both. Only the behavior of MG 3062 was different. On the other hand, aniline hydroxylation was enhanced by 2, 2'-bipyridine added in vitro while $\mathrm{O}$-de-ethylation of acetophenetidine was not (21), and benzpyrene pretreatment changed kinetics and $\mathrm{pH}$ optimum of aniline hydroxylation but not those for benzphetamine demethylation (22). N-Dealkylation of ethylmolphine, presumably catalyzed by the same enzyme that is responsible for $\mathrm{N}$-methylaniline demethylation (19), took place with solubilized microsomal syslem (23) while aniline was not hydroxylated. In p-methoxyacetanilide O-demethylation, activated oxygen attacks the methyl group leaving the carbon atom in the benzene ring intact (24), as previously postulated (1). Therefore, it is also probable that the resemblance is limited to aniline hydroxylation and p-anisidine O-demethylation. The stimulatory effect of acetone cannot be counted as a common characteristic of aromatic hydroxylation and O-demethylation; in accordance with Anders' observation (17), no other reaction so far studied including aromatic hydroxylation of benzene and $\mathrm{O}$-demethylation of o-nitroanisole was enhanced by the addition of acetone. Two side chain hydroxylation, i.e. that of $p$-nitrotoluene (2) and tolbutamide, were inhibited by the solvent. 
Similarity may be also pointed out in inhibition patterns between $p$-nitrotoluene hydroxylation (2) and p-chloro- $\mathrm{N}$-methylaniline demethylation; these two reactions were conpetitively inhibited by SKF 8742-A, SKF 525-A and Lilly 18947, and non-competitively by $A E D V$ and MG 3062. Furthermore, phenobarbital pretreatment resulted in a marked enhancement in Vmax's of the two reactions. This is to be expected as a) the two are sidechain hydroxylations (1), b) ethylbenzene is, in part, oxidized at the terminal carbon in the side chain when given to animals $(25,26)$ and oxygen is presumed to attack the carbon at the end of -N-C side chain in p-chloto-N-methylaniline N-demethylation (1). Further study is required with solubilized microsomal system $(23,27)$ in relation with multiplicity of p-450 (28 30$)$.

MG 3062, a potent inhibitor of hydroxylation of aniline and $p$-nitrotoluene as well as $\mathrm{N}$-demethylation of monomethylaminoantipyrine and $p$-chloro- $\mathrm{N}$-methylaniline, gave a biphasic effect on the $p$-anisidine demehylation with respect to the substrate concentration. When $p$-anisidine concentration was approx. $1.5 \div 10^{-4} \mathrm{M}$ or higher, MG 3062 was inhibitory even if slightly, while the compound stimulated the same reaction at the lower substrale concentration. Further study is now underway to elucidate the mechanism of this conflicting effect.

\section{SUMMARY}

No clear parallelism in hepatic activities was found among three demethylation reactions (i.e., N-demethylation of monoethylaminoantipyrine and p-chloro-N-methylaniline, and $\mathrm{O}$-demethylation of $p$-anisidine, when the rats were pretreated with phenobarbital and 3-methylcholanthrene. Inhibition types of AEDV, DPEA and their ethyl derivatives also varied depending on the demethylation studied. Thus, different enzyme systems or rate limiting components appear to be involved in the three demethylation reactions.

Marked similarities were observed in the responses to inducers and inhibitors between aromatic hydroxylation of aniline and $O$-demethylation of $p$-anisidine, and between side chain hydroxylation of $p$-nitrotoluene and $\mathrm{N}$-demethylation of $p$-chloro- $\mathrm{N}$-methylaniline. Possible explanations are discussed in relation to these observations.

Acelone produced stimulation in $p$-anisidine demethylation as well as aniline hydroxylation, but not in other reactions such as hydroxylation of benzene and tolbutamide nor demethylation of monomethylaminoantipyrine and o-nitroanisole.

Acknowledgements: The authors are grateful to Professor M. Nishio of Kyoto University for his support, and to Dr. S. Uemura of Kyoto University for synthesis of p-chloro$\mathrm{N}$-methylaniline. Thanks are also due to the following companies for their generous gifts of reagents: Nippon Shinyaku Co.; Ono Pharmaceutical Co.; Bochringer Mannheim Japan; Smith, Kline and French Laboratories; Lilly Research Laboratories; Ciba-Geigy L.td: and Maggioni \& C.S.p.A. 


\section{REFERENCES}

1) McMahov, R.F.: J. Phamaceut. Sci, 55, 457 (1966)

2) Ikeda, M., Ohtsuji, H. ANd Imamura. T,: Jap. J. Pharmac. 22, 483 (1972)

3) Roberts, R.M. nivd Vouit, P.J.: J. Am. Chem. Soc. 78, 4778 (1956)

4) I keda, M., Conney, A. H. ANd Burns, J.J.: J. Pharmac, exp. Ther. 162, 338 (1968)

5) Connfy, A.H., Miller, E.C. AND Miller, J.A.: Cancer Res. 16, 450 (1956)

6) Ikeda, M. ANd Ohtsuj, H.: Toxicol. appl. Pharmac. 20, 30 (1971)

7) Gillette, J.R.: J. biol. Chem. 234, 139 (1959)

8) Kuppfer, D. and Brgggeman, L.L.: Analyt, Biochem. 17, 502 (1966)

9) AXELROd, I.: Biochem. J. 63, 634 (1956)

10) IMAt, Y. AND SATO, R.: Biochim. Biophys. Acta 36, 571 (1959)

11) Netter, K.J.: Arch. exp. Path. Phamak. 238, 292 (1960)

12) (iIBBS, H.D.: J. biol. Chem. 72, 649 (1927)

13) TagG, J., Yasuda, D.M., Tanabt, M. and Mrtoma, C.: Biochem. Pharmac, 16, 143 (1967)

14) Forist, A.A., Miller, Jr, W.L., Krake, J. and Struck, W.A.: Proc. Soc. exp. Biol. Med. 96, $180(1957)$

15) Drxon, M. AND Webr, E.C.: tnzymes, Ed. 2, p. 327, Academic Press, New York (1964)

16 I.rmman, K.C.: Mol. Pharmac. 5, 1 (1969)

17) Anders, M.W.: Microsomes and Drig Oxidations, Ed. by Glllftte, J.R., Conney, A.H., Cosmidis, G..., Estarrook, R.W., Fouls, J.R. And Manniring, G.J., p. 533, ^cademic Press, New York (1969)

18) Grokgl, W.J. ANi TFrhly, T.R.: Mol. Pharmac. 4, 502 (1968)

19) Alvarlis, A.P. A\D Manniring, G.J.: Mol. Pharmac. 6, 206 (1970)

20) Andirs, N.W. and Manniring, G.J.: Mol. Pharmac. 2, 319 (1966)

21) Buhlfr, D.R. and Rasmusson, M.E.: Comp. Biochem. Physiol. 25, 223 (1968)

22) Rickert, D.E. ANd Fouts, J.R.: Biochem. Pharmac, 19, 381 (1970)

23) Li, A.Y.H., Stobel, H.W. And Coon, M.J.: Mol, Pharmac. 6, 213 (1970)

24) Rlnson, J., Weissbach, H. and Udenfrifnd, S.: Mol. Pharmac. 1, 145 (1965)

25) ElMasky, A.M., SMITh, J.N. AND Williams, R.T.: Biochem. J. 64, 50 (1956)

26) Bakke, O.M. AND Schfline, R.R.: Toxic. appl. Pharmac. 16, 691 (1970)

27) Mitani, F., Alvares, A.P., Sassa, S. and Kappas, A.: Mol. Pharmac. 7, 280 (1971)

28) Hildebrandt, A., Remmir, H. and Estabrook, R.W.: Biochem. biophys. Res. Commun. 30, 607 (1968)

29) Sladek, N.E. and Manniring, G.J.: Mol. Pharmac. 5, 186 (1969)

30) Shorman, D.W., Chapin, M.G. and Mannfring, G.J.: Mol. Pharmac. 5, 412 (1969) 